\title{
Fabrication of a Millinewton Force Sensor Using Low Temperature Co- fired Ceramic (LTCC) Technology ${ }^{1}$
}

\author{
Hansu Birol, Thomas Maeder, Ingo Nadzeyka, Marc Boers and Peter Ryser \\ Ecole Polytechnique Fédérale de Lausanne (EPFL) \\ Laboratoire de Production Microtechnique (LPM) \\ CH-1015 Lausanne, Switzerland \\ Tel: ++41 2169377 58, Fax: ++41216933891, E-mail: hansu.birol@epfl.ch
}

\begin{abstract}
This study is aimed at outlining the fabrication of a novel piezoresistive force sensor using LTCC technology, which operates at millinewton range, yet is compatible with low cost thick-film fabrication process. Mechanical and electrical characterization of the device is explained in terms of processing conditions, including the principle of force sensing and materials employed. The improvement of device functionality by modifying commerciallyavailable thick-film conductors is described. The sensors are found to be efficient in responding to forces below $100 \mathrm{mN}$.
\end{abstract}

Keywords: LTCC, force sensor, piezoresistivity, co-firing.

\section{Introduction}

LTCC technology has been recently used for fabrication of various types of sensors [1-4]. LTCC sheets containing binders and plasticizers provide an ease of handling and structuring, which is an advantage for building 3-D devices [5]. This is enhanced by printing thick-film materials such as conductors, resistors, inductors, etc. Utilization of such components both on and in the LTCC packages increases the device functionality at reduced volumes. Full density attainable at low temperatures, chemical stability and hermeticity are some other advantages for sensor applications [6-8].

The main disadvantage of the technology, however, is the physical and chemical incompatibility of many thick-film materials with LTCC sheets [9-11]. The former type of defect is observed as warpage due to the shrinkage difference between the LTCC sheet and the deposited films, warpage, etc, whereas the latter is related to the chemical interaction between different components. These issues have to be well-known and controlled for reliable fabrication of the components.

Therefore the purpose of this work is: i. to introduce a millinewton force sensor fabricated using LTCC technology, as an alternative to alumina-based version, ii. to highlight the principle of sensing and important processing parameters, iii. to demonstrate the relation between materials compatibility and device performance. Instruments for push-test, resistance measurement and signal evaluation are used in addition to SEM (scanning electron microscopy) and dilatometer analysis to evaluate the results.

1 Published as: Birol-H Maeder-T Nadzeyka-I Boers-M Ryser-P, "Fabrication of a millinewton force sensor using low temperature co-fired ceramic (LTCC) technology", Sensors and Actuators A 134, 334-338, 2007, doi: dx.doi.org/10.1016/j.sna.2006.05.025 


\section{Motivation of the study / Selection of LTCC}

The force sensor is composed of two main parts: the LTCC beam, where the force is applied and the mechanical base. The beam is printed with thick-film piezoresistors, which convert mechanical strain (from force or pressure), into a change of resistance according to:

$\mathrm{G}_{\mathrm{f}}=(\Delta \mathrm{R} / \mathrm{R}) /(\Delta \mathrm{l} / \mathrm{l})=$ Signal $/ \varepsilon \ldots(1)$

where $\mathrm{G}_{f}, \mathrm{R}$ and 1 are the gauge factor, resistance and length, respectively. The numerator indicates the resistivity change (signal), whereas the denominator shows the strain $(\varepsilon)$ upon applied force on the material.

From (1), it is clearly seen that improved signal can be achieved by increased strain, which is difficult for low forces with standard alumina substrates. The key relations between the materials properties and the force sensor functions are given by:

$\mathrm{E}=\sigma / \varepsilon \ldots(2)$ and

$\sigma=(6 \mathrm{FL}) / \mathrm{bh}^{2} \ldots(3)$

where E, $\sigma$ and $\mathrm{F}$ are Young's modulus, stress and force. The geometrical constraints are represented by L, b and $h$, which stand for the length, width and thickness of the beam (figure 1). The previous relations can be further formulated as:

$\varepsilon_{\mathrm{LTCC}} / \varepsilon_{\mathrm{A} 12 \mathrm{O} 3}=\left(\mathrm{b}_{\mathrm{Al} 2 \mathrm{O} 3} \cdot \mathrm{h}^{2}{ }_{\mathrm{Al} 2 \mathrm{O} 3} \cdot \mathrm{E}_{\mathrm{Al} 2 \mathrm{O} 3}\right) /\left(\mathrm{b}_{\mathrm{LTCC}} \cdot \mathrm{h}_{\mathrm{LTCC}}^{2} \cdot \mathrm{E}_{\mathrm{LTCC}}\right) \ldots(4)$

which is obtained by assuming identical force applied on the beams with same length. It is important to note that strain and elastic constant are material characteristics and width and thickness can be defined by processability of the selected material.

Table I shows the comparison between the two materials in terms of the parameters shown in (4). Although the long-term design strains are similar, the LTCC, through its much lower modulus, availability of very thin sheets and possibility of 3D structuration, allows much higher sensitivity than alumina, making it especially suited to applications in the low force range.

3D structuration allows several improvements. First, using, at the point of measurement, a thick and narrow bottom layer and a thin and wide top layer (figure 2) maximizes the degree of compressive strain at the bottom / measuring resistor (which determines the signal), compared to the tensile strain at the top side (which governs fracture). Therefore, the response is improved [12]. Additionally, restricting the narrowing of the bottom layer to the measurement zone increases the overall stiffness of the sensor, while allowing for better defined boundary conditions (less influence of parasitic stresses due to mounting on the base).

\section{Experimental}

The beam of the millinewton force sensor can be analyzed in terms of its mechanical structure and functional elements. It consists of top and bottom LTCC layers (figure 3), which are screen-printed, laminated under a uni-axial press that is heated to $70{ }^{\circ} \mathrm{C}(25 \mathrm{MPa})$ 
and co-fired at $875^{\circ} \mathrm{C}$, in air. The top layer, where the force is applied, is kept under tension, whereas the bottom layer is under compression. The compressive strain is maximized at specially- designed neck regions in the bottom layer, which carry the measurement resistors (figure 4). This layer also carries the other (inactive) half of the measurement bridge, which can therefore be deposited in a single screen printing step.

Terminations are selected from $\mathrm{Au} \mathrm{[16]} \mathrm{and} \mathrm{Ag} / \mathrm{Pd}(3 / 1)$ pastes (table II), the latter one being co-firable with LTCC [17]. To our experience, however, both conductors pose different problems. The organometallic Au paste, which has a very fine fired thickness, may become discontinuous as a buried layer due to islanding, and at the vias due to reactions with Ag-based materials [10]. The deformation due to the $\mathrm{Ag} / \mathrm{Pd}$ paste, although very with thick LTCC structures, is far too high in the case of the thin LTCC beams that are the object of our study.

Therefore, we prepared a third paste by mixing another commercial paste (Du Pont 9473 $\mathrm{Ag} / \mathrm{Pd}$ ) with $20 \%$ by weight quartz (Sihelco, Sikron B 600). $\mathrm{SiO}_{2}$ is selected due to its network forming character [18], which, in practice, increases the onset of shrinkage temperature. The shrinkage behavior of the modified paste (from here on) and its pure, commercial form is studied by dilatometer analysis, which is shown in figure 5. Moreover, comparison of warpage in co-fired LTCC samples using these pastes can be seen in figure 6 . These results, which suggest warpage-free production of thinner LTCC sheets for beams, facilitated fabrication of sensors with increased performance.

The thick-film components used and their functions are shown in table II. Common to all, solder contacts between the beam and the mechanical support and via filling are made using solderable $\mathrm{Ag} / \mathrm{Pd}$ (Du Pont 6146). On the other hand, all of the three terminations, $\mathrm{Au}, \mathrm{Ag} / \mathrm{Pd}$ and modified paste, are used individually to evaluate their shrinkage compatibility with LTCC (visual observation). Overall, the modified $\mathrm{Ag} / \mathrm{Pd}$ paste resulted in the minimum warpage after firing. Therefore, this material was selected for the beams used for electrical characterization.

\section{Results}

\section{Mechanical characterization}

Mechanical tests were conducted in two variants: i. the effect of LTCC layer thickness and its orientation, in light of a previously-made theoretical study [13], ii. the effect of printed pastes on mechanical performance of the sensors.

In the former study, we laminated top and bottom LTCC layers of the beam at different thicknesses using Du Pont series of LTCC sheets (254 (951-AX) and 116 (951-AT) $\mu \mathrm{m}$ thick). The bottom layer, which we selected relatively thicker than the top layer, was expected to yield a higher signal to tensile stress ratio (see above), by positioning the neutral plane close to the top side [13].

The tests were conducted by using a push-test instrument (Royce Instruments), which recorded the gradually-increasing stress applied on the beam until the fracture. The results of mechanical testing are given in table III (beams without thick films) and IV (with conductors $\&$ resistors), together with the corresponding calculated strength values [13]. 
Globally, the strength levels agree well, achieving typical values around $300 \mathrm{MPa}$. In some cases, the strength appears to be much higher (bare 116/254 and 254/116+AgPd). This is probably due, especially in the case of $\mathrm{AgPd}$, to warpage of the samples, which has a stiffening effect by modifying the shape of the cross section.

Strength values of bare and covered beams are roughly similar: we did not observe a strong decrease in the substrate strength due to chemical interactions [20].

\section{Electrical characterization}

The fabricated beams were soldered on the mechanical support of the sensor and the force was applied by hanging weights on the beams. The output of the Wheatstone measurement bridge supplied with $5.00 \mathrm{~V}$, was used to characterize the response due to applied force. Used materials, beam layer configurations, fired thicknesses and the voltage changes recorded at $200 \mathrm{mN}$ are listed in table $\mathrm{V}$ and the summary of the electrical characterization is shown in figure 7. Table $\mathrm{V}$ also gives approximate calculated responses (with $\mathrm{G}_{\mathrm{F}}$ assumed to be 12).

As expected, thinner LTCC beams give a higher response than thicker ones. Also, the $116 / 254$ configuration is more sensitive than the $254 / 116$ one, according to the calculations. In spite of their half bridge design (only 2 active resistors), the LTCC beams are more sensitive than the reference alumina one (full bridge, 4 active resistors).

However, the sensitivity of the two thinnest beams is much lower than expected. This is ascribed to a strong stiffening effect brought about by warpage of the measurement cross section.

\section{Conclusions}

It is shown that LTCC is a promising material to replace the traditional alumina for the application under study. Its elastic modulus, available thickness and ease of processing allow fabrication of LTCC beams having sensitivities several times higher than that of alumina.

However, additional work on the beam configuration and on compatibility of thick-film materials with LTCC is needed to achieve the full potential of the present design at low thicknesses, which is at present limited by excessive warpage upon sintering. This will mainly be accomplished by improvements in the formulation of the conductor pastes, to achieve better shrinkage compatibility with LTCC.

\section{Acknowledgements}

The writers are thankful to Ms. Caroline Jacq and Mr. Giancarlo Corradini of Laboratory for Production of Microtechnology (LPM) at EPFL for their useful discussions. 


\section{References}

[1] J. Kita, A. Dziedzic, L.J.Golonka and A. Bochenek, "Properties of laser cut LTCC heaters", Microelectron. Reliab., Vol. 40, 2000, pp. 1005-1010.

[2] H.Teterycz, L.J.Golonka, J.Kita, R.Bauer, B.W. Licznerski, K. Nitsch and K. Wisniewski, "New design of an SnO2 gas Sensor on LTCC", Sensor Actuat B-Chem, Vol. 47, 1998, pp. 100-103.

[3] M.G-Rubio, L.S.-Laguna, M. Smith and J.J.S.-Aviles, "LTCC technology multilayer Eddycurrent proximity sensor for harsh environments", International Symposium on Microelectronics, 1999, pp. 676-681.

[4] M.G-Rubio, L.M.S-Laguna, P.J. Moffett and J.J.S-Aviles, "The utilization of LTCC-ML technology for meso-scale EMS, a simple thermistor based flow sensor", Sensor Actuat, Vol. 73, 1999, pp. 215-221.

[5] H. Birol, T. Maeder and P. Ryser, "Processing of Graphite-Based Sacrificial Layer for Microfabrication of Low Temperature Co-fired Ceramics (LTCC)", in publication in the Sensors and Actuators A, 2006.

[6] H. Jantunen, A novel low temperature co-firing ceramic (LTCC) material for telecommunication devices, PhD. Thesis, University of Oulu, Finland, 2001.

[7] M. Eberstein and W.A. Schiller, Development of high-permittivity glasses for microwave LTCC tapes, Glass Sci. Technol., Vol. 76 (1), 2003, pp. 816.

[8] S. Nishigaki and J. Fukuta, Low temperature, cofirable, multilayered ceramics bearing pure $\mathrm{Ag}$ conductors and their sintering behavior, Adv. Ceram., Vol. 26, 1989, pp. 199215.

[9] H. Birol, T. Maeder and P. Ryser, "Influence of Processing and Conduction Materials on Properties of Co-fired Resistors in LTCC Structures", J. Eur. Ceram. Soc., available online.

[10] H. Birol, T. Maeder, C. Jacq and P. Ryser, "Investigation of Interactions Between Co-fired LTCC Components", J. Eur. Ceram. Soc., Vol 25 [12], 2005, pp. 2065-2069.

[11] H. Birol, T. Maeder and P. Ryser, "Materials Compatibility Issues in LTCC Technology and Their Effects on Structural and Electrical Properties", Proceedings of the 1st CICMT Conference on Ceramic Interconnect Technology, Baltimore-USA, 2005, pp. 300-309.

[12] H. Birol, M. Boers, T. Maeder, G. Corradini and P. Ryser, "Design and processing of lowrange piezoresistive LTCC force sensors", Proceedings of the XXIX International Conference of IMAPS Poland Chapter, Koszalin-Darlowko, 2005.

[13] M. Santo-Zarnik, D. Belavic, "Construction of a PZT actuator in an LTCC structure - a preliminary finite-element analysis", Proceedings, XXVIII International Conference of IMAPS Poland Chapter, 2004, pp. 366-370.

[14] http://www.dupont.com/mcm/gtapesys/part4.html

[15] http://global.kyocera.com/prdct/fc/product/material/elec/

[16] http://www.electroscience.com/pdf/8837.pdf

[17] http://www2.dupont.com/MCM/en_US/PDF/datasheets/6146.pdf

[18] R.C. Sutterling, G.O. Dayton and J.V.Biggers "Thick-film resistor/dielectric interactions in a LTCC package", IEEE Trans. Comp. Pack. Manuf. Tech., Vol. 18, Part B, 1995, pp. 346-351.

[19] D. Belavič, M. Hrovat, A. Benčan, L. J. Golonka, A. Dziedzic, J. Kita, "Thick-film resistors on LTCC for possible sensor applications", V: MIXDES 2002 : Proceedings of the 9th International Conference Mixed Design of Intergrated Circuits and Systems : Wrocław, Poland, 2002, pp. 20-22.

[20] T. Maeder, C. Jacq, H.Birol and P. Ryser, "High-strength ceramic substrates for thick film sensor applications", Proceedings, IMAPS Friedrichshafen, Germany, 2003, pp. 133-137. 


\section{Figure Captions}

Figure 1. The beam from profile and top.

Figure 2. The cross section of the beam. Width and thickness of the layers are shown as $b$ and h, respectively and $\delta$ is the distance of the neutral plane to the planes' normal.

Figure 3. Individual layers of one single beam that is scored from a fired, $2 \mathrm{X} 10$ set of multiple beams. Unfired dimension is around of $18 \mathrm{~mm} \times 4 \mathrm{~mm}$.

Figure 4. The finished beam $\left(\sim 15 \times 3 \mathrm{~mm}^{2}\right)$ with active (right) and passive piezoresistors and large rectangle area for soldering.

Figure 5. Dilatometer analysis showing the shrinkage delay of modified Ag-Pd paste by 140 ${ }^{\circ} \mathrm{C}$ and its reduced overall shrinkage $(21 \%)$.

Figure 6. Comparison of test patterns co-fired with pure and modified Ag-Pd pastes. Latter shows reduced warpage on both faces of samples.

Figure 7. Signal change at $200 \mathrm{mN}$. Alumina used has a thickness of $250 \mu \mathrm{m}$. 


\section{Biographies}

Hansu Birol received his BSc degree in Materials Science and Engineering from Middle East Technical University, Ankara, Turkey in 1999 and MSc degree in Sensor Systems and Technologies from Karlsruhe University of Applied Sciences, Germany in 2001. Currently he is doing his $\mathrm{PhD}$ at Swiss Federal Institute of Technology, EPFL, Switzerland, at the Microengineering Department. His current research interests are optimization of physical and chemical materials incompatibilities within low temperature co-fired ceramics (LTCC) system and fabrication of LTCC-based microfluidic devices for sensor applications.

Thomas Maeder pursued with a $\mathrm{PhD}$ in piezoelectric thin films, and a post-doc at IBM Rüschlikon in single-crystal conductive oxides, after graduating from the Ecole Polytechnique Fédérale de Lausanne (EPFL) in materials science. He now heads the thickfilm technology group at the EPFL, where current areas of interest are thick-film and LTCC technology for advanced sensor and packaging applications, and sensor networking.

Ingo Nadzeyka recieved his BSc degree in Mechanical Engineering from the RheinischWestfälische Technische Hochschule, Aachen, Germany in 2003. Currently he is doing his MSc/Diploma Thesis in the field of Micro production technology at the same university.

Marc Boers will obtain his master degree in microengineering from the Ecole Polytechnique Fédérale de Lausanne (EPFL) in 2006. Currently he is doing his master thesis work at the Microsystems Technology (MST) group of the Royal Institute of Technology (KTH) in Stockholm, on MEMS wafer-level packaging for infrared bolometer sensors.

Peter Ryser, Swiss citizen, received a Master degree in Physics (University Neuchâtel 1979), a $\mathrm{PhD}$ in applied Physics (University Geneva 1985) and a Masters Degree in Corporate Management (Lucerne 1993). His professional background includes several R\&D activities. From 1990-1998 he was the head of research at Siemens Building Technologies. Since 1999 Peter Ryser is Professor at the Swiss Federal Institute of Technology EPFL in Lausanne and act as a director for the micro engineering section. 


\section{Tables}

Table I. LTCC versus alumina as the beam material

\begin{tabular}{|l|c|c|}
\hline \multicolumn{1}{|c|}{ Properties } & $\begin{array}{c}\text { Du Pont LTCC } \\
\mathbf{9 5 1} \text { (fired) }\end{array}$ & $\begin{array}{c}\text { Kyocera A-476 } \\
\mathbf{A l}_{\mathbf{2}} \mathbf{O}_{\mathbf{3}} \mathbf{( 9 6 \% )}\end{array}$ \\
\hline Elastic modulus (GPa) & $110^{[13]}$ & $330^{[15]}$ \\
\hline 10-year design stress $(\mathrm{MPa})$ & $110^{[12]}$ & $270^{[12]}$ \\
\hline 10-year design strain $(\mathrm{ppm})$ & $10^{[12]}$ & $800^{[12]}$ \\
\hline Available thickness $(\mathrm{mm})$ & $0.04-0.21^{[14]}$ & $0.25-1.00^{[15]}$ \\
\hline
\end{tabular}

Table II. Thick-film components used

\begin{tabular}{|c|c|c|}
\hline Commercial name & Specification & Location in the sensor \\
\hline ESL 8837 & Organometallic $\mathrm{Au}[16]$ & Buried / in vias \\
\hline Du Pont 6146 & Co-firable, solderable $\mathrm{Ag} / \mathrm{Pd}$ & $\begin{array}{c}\text { Buried / on solder contact } \\
/ \text { in vias }\end{array}$ \\
\hline (Du Pont 9473$)$ & Modified $\left(20\right.$ weight $\left.\% \mathrm{SiO}_{2}\right)$ & Buried / in vias \\
\hline Du Pont 2041 & Piezoresistor $\left(\mathrm{RuO}_{2}+\text { ruthenate }\right)^{[19]}$ & Sensing element \\
\hline
\end{tabular}

Table III. Effect of layer configuration on the fracture strength of the beams * Average values \pm standard deviation

\begin{tabular}{|l|c|c|c|c|}
\hline Top / bottom layer thickness $(\boldsymbol{\mu m})$ & $\mathbf{2 5 4} / \mathbf{2 5 4}$ & $\mathbf{1 1 6} / \mathbf{1 1 6}$ & $\mathbf{2 5 4} / \mathbf{1 1 6}$ & $\mathbf{1 1 6} / \mathbf{2 5 4}$ \\
\hline Number of beams used & 30 & 16 & 31 & 31 \\
\hline Average force at fracture $(\mathrm{mN})^{*}$ & $2452 \pm 215$ & $598 \pm 63$ & $1333 \pm 153$ & $1615 \pm 172$ \\
\hline Calculated stress [13] & $320 \pm 28$ & $344 \pm 36$ & $311 \pm 36$ & $382 \pm 41$ \\
\hline
\end{tabular}

Table IV. Effect of printed thick-film components on the fracture strength of the beams * Average value \pm standard deviation

\begin{tabular}{|l|c|c|c|c|c|c|}
\hline Layer configuration & \multicolumn{3}{|c|}{$\mathbf{2 5 4 / 1 1 6}$} & \multicolumn{3}{|c|}{$\mathbf{1 1 6} / \mathbf{2 5 4}$} \\
\hline Conductor used & $\mathrm{Au}$ & $\mathrm{Ag} / \mathrm{Pd}$ & modified & $\mathrm{Au}$ & $\mathrm{Ag} / \mathrm{Pd}$ & modified \\
\hline Number of beams used & 15 & 12 & 15 & 13 & 14 & 14 \\
\hline Force at fracture $(\mathrm{mN}) *$ & $1230 \pm 316$ & $1876 \pm 685$ & $1309 \pm 292$ & $1195 \pm 193$ & $1304 \pm 188$ & $1260 \pm 203$ \\
\hline Calc. stress $[13]$ & $287 \pm 74$ & $437 \pm 160$ & $305 \pm 68$ & $282 \pm 46$ & $308 \pm 44$ & $298 \pm 48$ \\
\hline
\end{tabular}

(Beams have also piezoresistors printed on)

Table V. Electrical characterization of the fabricated beams

*Alumina: MillINewton force sensing cell (full bridge)

\begin{tabular}{|l|c|c|c|c|}
\hline \multicolumn{1}{|c|}{ Material } & Configuration & $\begin{array}{c}\text { Fired thickness } \\
(\boldsymbol{\mu m})\end{array}$ & $\begin{array}{c}\text { Delta Voltage at } \\
\mathbf{2 0 0} \mathbf{~ m N}(\mathbf{m V})\end{array}$ & $\begin{array}{c}\text { Approx. calculated } \\
\text { response }(\mathbf{m V})\end{array}$ \\
\hline Alumina* & Substrate & 250 & 7.50 & 6.4 \\
\hline LTCC & $254 / 116$ & 290 & 12.00 & 14 \\
\hline LTCC & $116 / 254$ & 290 & 14.80 & 17 \\
\hline LTCC & $116 / 116$ & 180 & 15.35 & 39 \\
\hline LTCC & $116 / 50$ & 130 & 36.90 & 64 \\
\hline
\end{tabular}




\section{Figures}

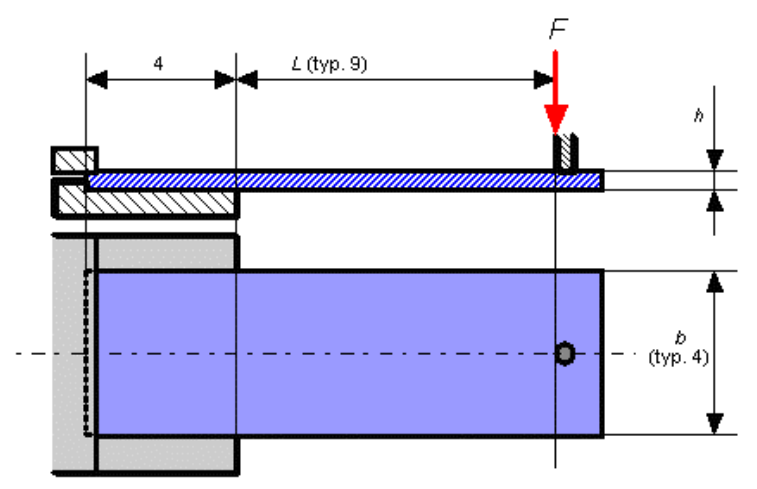

Figure 1. The beam from profile and top.

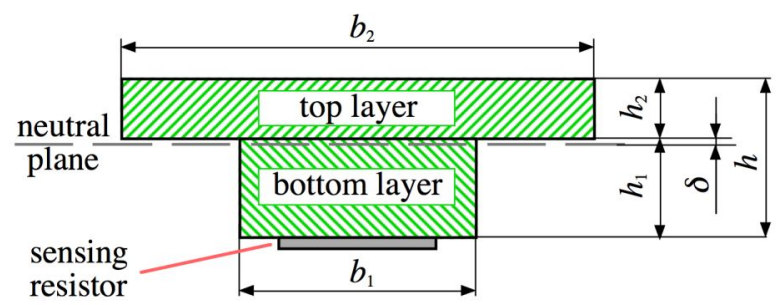

Figure 2. The cross section of the beam. Width and thickness of the layers are shown as $b$ and h, respectively and $\delta$ is the distance of the neutral plane to the planes' normal.

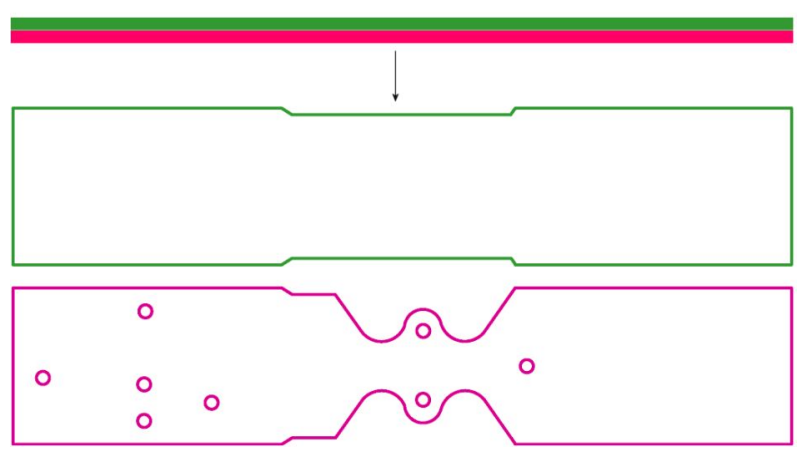

Figure 3. Individual layers of one single beam that is scored from a fired, $2 \times 10$ set of multiple beams. Unfired dimension is around of $18 \mathrm{~mm} \times 4 \mathrm{~mm}$.

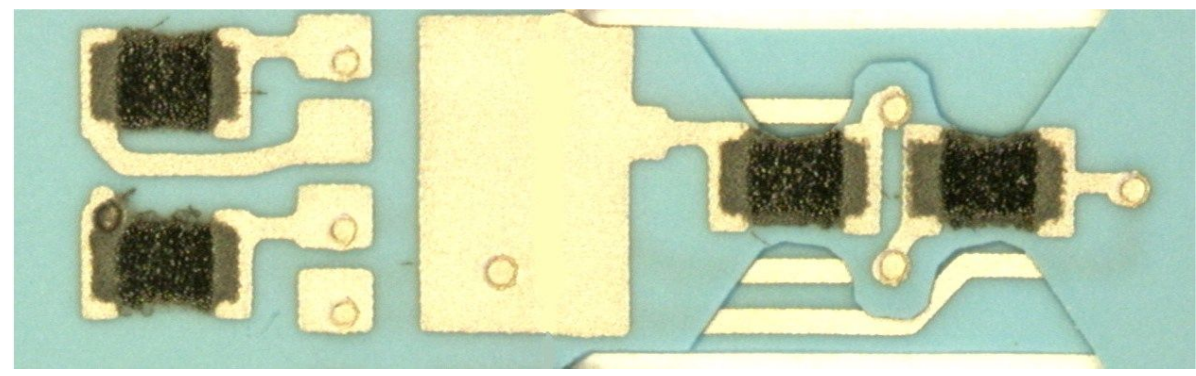

Figure 4. The finished beam $\left(\sim 15 \times 3 \mathrm{~mm}^{2}\right)$ with active (right) and passive piezoresistors and large rectangle area for soldering. 


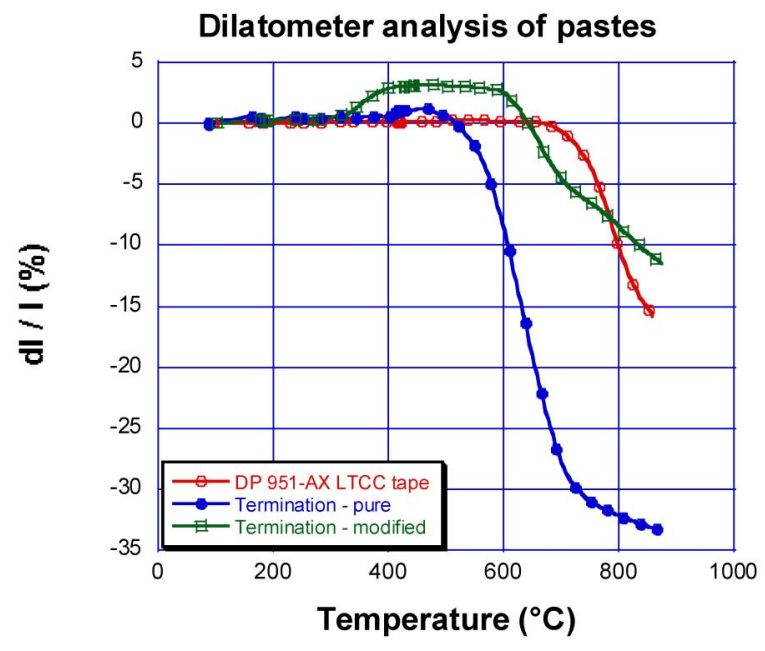

Figure 5. Dilatometer analysis showing the shrinkage delay of modified Ag-Pd paste by 140 ${ }^{\circ} \mathrm{C}$ and its reduced overall shrinkage $(21 \%)$.

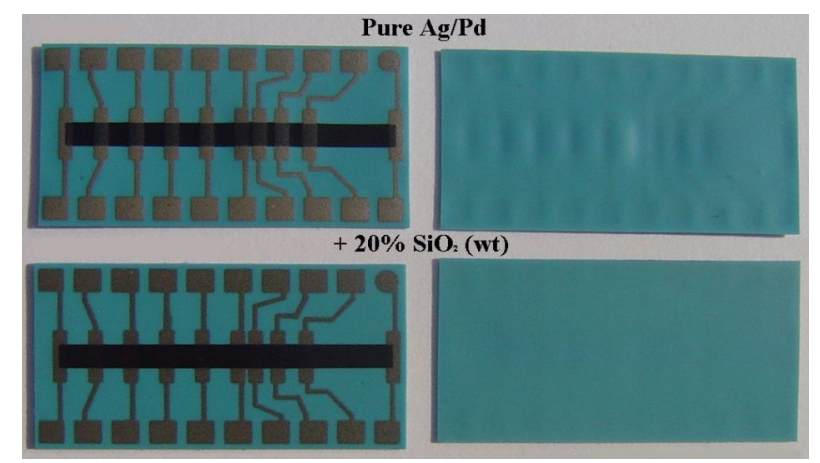

Figure 6. Comparison of test patterns co-fired with pure and modified Ag-Pd pastes. Latter shows reduced warpage on both faces of samples.

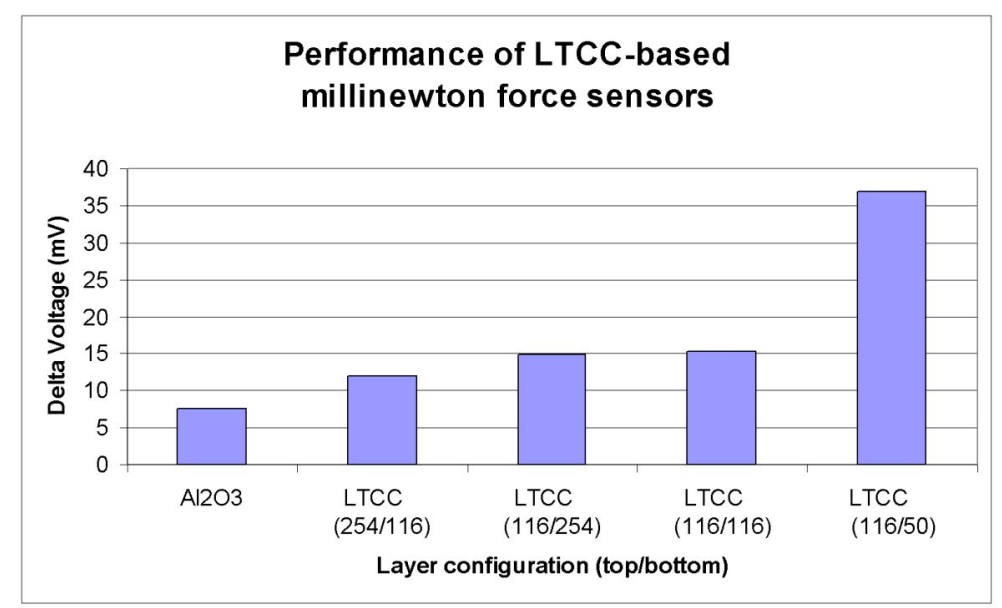

Figure 7. Signal change at $200 \mathrm{mN}$. Alumina used has a thickness of $250 \mu \mathrm{m}$. 